\title{
Hacia una ecología política del agua
}
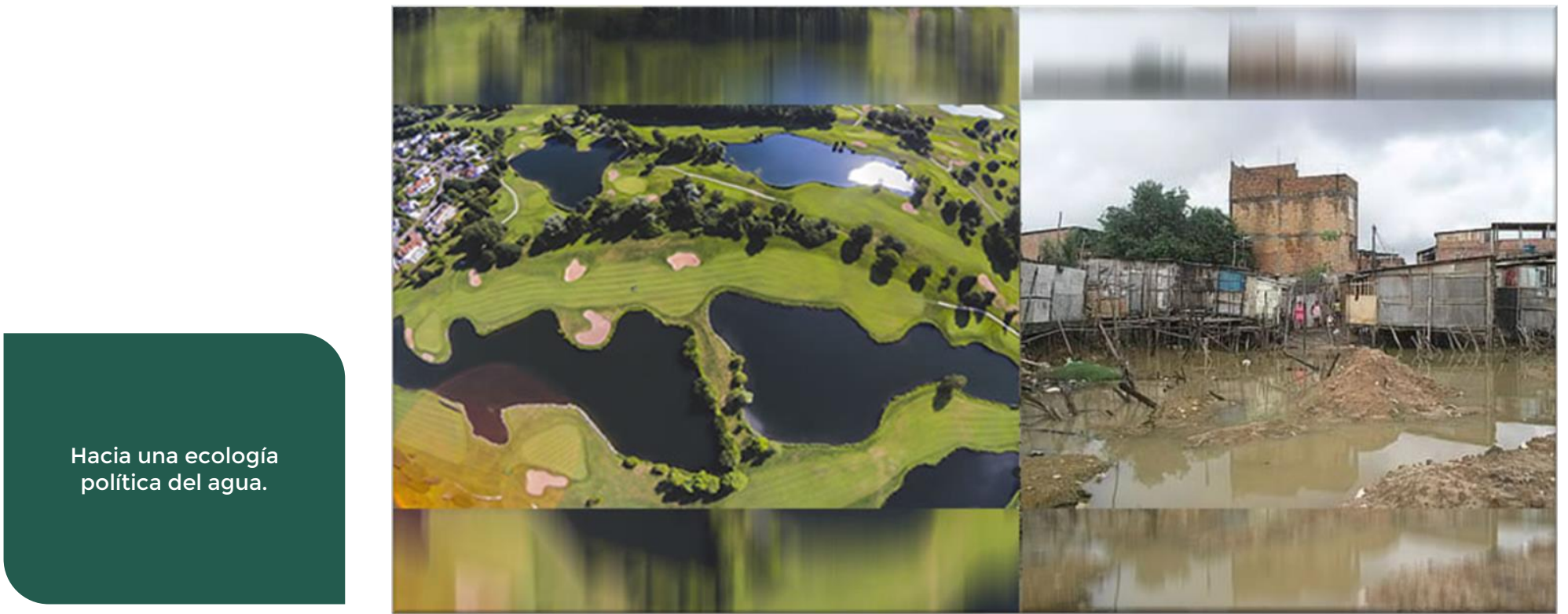

En la actualidad, la creciente acumulación de capital demanda una explotación y transformación mayor del entorno natural y social con implicaciones desiguales y, a veces, irreversibles (Delgado, 2013).

En 2015, el Informe Riqueza Global reportaba que el 0.7 \% de la población mundial poseía el 45.3 \% de la riqueza global; mientras que el $71 \%$ solo contaba con el $3 \%$ de esta'.

El resultado de ello es un mundo más inequitativo, con un acelerado proceso de transformación de la naturaleza que busca acumular más capital, que altera los ecosistemas a escala mundial y que se vincula a crisis económicas, a la especulación en el mercado de la tierra y a mecanismos de despojo de recursos naturales en todo el mundo. Todo ello dibuja un panorama de afectaciones y conflictos socioambientales. Así, en 2015, el proyecto EJOLT (Environmental Justice Organizations, Liabilities and Trade [Organizaciones de Justicia Ambiental, Responsabilidades y Comercio], 2011-2015) tenía registrados 1,500 casos de conflictos. En el caso de México, la Semarnat publicó recientemente que tiene detectados 560 conflictos ambientales, de los cuales 86 son hídricos.

Desde las ciencias sociales, se reconoce que las transformaciones en la naturaleza tienen raíces políticas y que están estrechamente relacionadas con condiciones económicas desiguales y procesos de 
PERSPECTIVAS IMTA (0)

$N^{\circ} .17,2020$

MEDIO AMBIENTE

Autor: Amalia Salgado López

DOI: $\underline{\text { doi.org/10.24850/b-imta-perspectivas-2020-17 }}$

dominación que genera el sistema económico (Ávila-García, 2016; Escobar, 2014; Leff, 2003; Martínez Alier, 2015). Una de las aproximaciones teóricas que devela las causas y no solo los síntomas es la ecología política, marco analítico que juega un papel preponderantemente reordenador del mundo.

\section{La ecología política: Un marco analítico para entender la complejidad del agua}

Diversas fuentes de conocimiento nutren a la ecología política, desde la ecología profunda (Naess), el ecosocialismo (O'Connor) y el ecoanarquismo (Bookchin) (Leff, 2003). La ecología política parte de la idea de que los cambios ambientales no son procesos neutrales y que las problemáticas socioambientales mantienen una serie de proposiciones que, aunque inmersos en una infinidad de temas, se pueden identificar claramente. En este sentido, Bryant y Bailey (1997) explican que los problemas ambientales son una manifestación de fuerzas políticas y económicas más amplias asociadas con la propagación mundial del capitalismo y sugieren tres premisas básicas:

1. Aceptar que los costos y beneficios asociados con el cambio climático ambiental están distribuidos entre distintos actores de manera desigual;

2. que lo anterior refuerza o reduce las desigualdades económicas y sociales existentes;

3. y que ello altera el poder de unos actores en relación con otros.

Para Leff (2003), la ecología política explora con nueva luz las relaciones de poder que se entretejen entre los mundos de vida de las personas y el mundo globalizado, donde confluyen "las ramificaciones ambientales y ecológicas de nuevas disciplinas: la economía ecológica, el derecho ambiental, la sociología política, la antropología de las relaciones cultura-naturaleza y la ética política" (Leff, 2003: 2). A la ecología política le interesa dar cuenta de cómo el poder político incide en los conflictos socioambientales, por lo que una corriente de pensamiento centra su estudio en el metabolismo social y los conflictos ecológicos distributivos, lo que "permite develar los términos de intercambio, el déficit físico existente en el comercio internacional de los países pobres y los pasivos ambientales asociados" (Martínez Alier, 2015).

Explica Toledo (2013) que el metabolismo social emana de una concepción marxista que parte de una metáfora biológica para ilustrar la circulación de las mercancías o bien para comprender el intercambio entre sociedad y naturaleza. Este metabolismo contiene dos dimensiones: una dimensión material, visible o tangible y otra inmaterial, invisible o intangible, las cuales pueden ser representadas en cinco etapas: la apropiación, la transformación, la circulación, el consumo y la excreción. Este marco analítico tiene potenciales alcances para comprender los problemas sociohídricos, a partir de un ensamblaje de valores, sentidos y lenguajes, que permiten superar la dicotomía naturaleza/cultura y observar el problema del agua como una interconexión de intereses, intenciones, disputas y expectativas, que reflejan la desigualdad económica.

Otro enfoque de la ecología política que puede ser útil analíticamente para entender los problemas sociohídricos es la acumulación por desposesión (Ávila-García, 2016; Harvey, 2004; Swyngedouw, 2005), que nos ayuda a analizar la mercantilización de la naturaleza en todas sus formas, la cual atenta contra entornos naturales y poblaciones que habitan en esos territorios.

Al tomar en cuenta lo antes expuesto, podemos observar que la ecología política no solo examina el campo del poder que se establece dentro del conflicto de intereses por la apropiación de la naturaleza, sino que a su vez nos invita a repensar la política desde una nueva visión de las relaciones de la 
PERSPECTIVAS IMTA (0)

$N^{\circ} .17,2020$

Autor: Amalia Salgado López

DOI: doi.org/10.24850/b-imta-perspectivas-2020-17

naturaleza, la cultura y la tecnología. En este sentido, "la ecología política se funda en un nuevo pensamiento y en una nueva ética: una ética política para renovar el sentido de la vida" (Leff, 2003).

El reto está en utilizar a la ecología política como un marco analítico que facilite la reducción de brechas de desigualdad económica y social que sufrimos en México. El gran riesgo está en la polarización de las posiciones, que cierren el diálogo e impidan construir acuerdos en beneficio de todas y todos, para mantener el statu quo de desigualdad.

La ecología política permite reconocer las diferentes posiciones de una gran diversidad de actores (empresarios, indígenas, académicos) desde una mirada crítica para transitar hacia nuevas formas de comprensión y relaciones de poder que mejoren la toma de decisiones en la política; aventura que es muy complicada, pero que sin duda representa una misión que merece la pena emprender, al menos desde el terreno de la academia y el quehacer del IMTA.

Bibliografía

Ávila-García, P. (2016). Hacia una ecología política del agua en Latinoamérica. Revista de Estudios Sociales, 55, 18-31.

Bryant, R. L., \& Bailey, S. (1997). Third world political ecology. Psychology Press.

Delgado Ramos, G. C. (2013). ¿Por qué es importante la ecología política? Nueva Sociedad, 244, 47-60.

Escobar, A. (2014). Territorios de diferencia: lugar, movimientos, vida, redes. Editorial Universidad del Cauca.

Harvey, D. (2004). El" nuevo" imperialismo: acumulación por desposesión. Socialist Register.

Leff, E. (2003). La ecología política en América Latina. Un campo en construcción. Polis. Revista Latinoamericana, 5.

Martínez Alier, J. (2015). Ecología política del extractivismo y justicia socio-ambiental. Interdisciplina, 3(7).

Swyngedouw, E. (2005). Dispossessing H2O: the contested terrain of water privatization. Capitalism Nature Socialism, 16(1), 81-98.

Toledo, V. M. (2013). El metabolismo social: una nueva teoría socioecológica. Relaciones. Estudios de Historia y Sociedad, 34(136), 41-71.

[1] https://www.credit-suisse.com/about-us-news/en/articles/news-and-expertise/global-wealth-in-2015underlying-trends-remain-positive-201510.html 